\title{
Exploring the use of Standardised design in addressing the shortage of primary school places in the UK
}

\author{
Alex Opoku \\ Bartlett School of Construction and Project Management, University College London, London, UK \\ Sarah A. Mills \\ Willmott Dixon, Hitchin, UK
}

Purpose - As part of the UK Government's strategy to address the current shortage of primary school places is the construction of standardised designed schools. The UK government has been facing an uphill battle to meet the demand for the ever-increasing number of school places it requires. This paper seeks to explore the use of standardised school design in addressing the problem of primary school places in the UK.

Methodology/Approach - Due to the exploratory nature of this investigation, a pragmatic research philosophy is utilised and mixed method data collection techniques are employed. Quantitative data collection is in the form of a survey involving 306 construction professionals and stakeholders; this has been consolidated using qualitative data collection in the form of nine purposefully selected semi-structured interviews.

Findings - The research highlighted the influence that people and their perceptions have on the successful implementation of standardisation. The results show that a high level of misunderstanding exists around the concept of standardisation and its definition. Standardised design has shown to have a remarkable influence in reducing the cost and time required for delivering the construction of new schools.

Limitations - Due to the exploratory nature of this research the results obtained have not been wholly conclusive but have instead provided a contribution to the area of standardisation in construction.

Originality - The research has uncovered that, in order to truly promote and drive standardisation in the delivery of schools, a joint approach is required with designers, contractors, clients and manufacturers, working in partnership to develop successful solutions. The paper will therefore help the key stakeholders delivering standardised schools in UK to fully understand the concept and turn the challenges into opportunities.

Keywords: Building Standardisation, Schools buildings, School places, Standardised design, United Kingdom, 


\section{Introduction}

The Department for Education (DfE) has suffered a drastically diminished budget (Omigie, 2014 ) in a recovering economy where construction prices are increasing quickly (Richardson, 2016). The situation has intensified with the decision by the HM Treasury to schedule an average of 17\% real-term spending cut to Government departments between 2015 and 2019. A particular concern is that there is no commitment to protect the schools or education budget which had previously been ring-fenced by the Coalition Government (Omigie, 2014). It is estimated that the budget shortfall is expected to rise to $£ 4.6$ billion by 2018-19 (Omigie, 2014). This has the potential to have drastic impact on the construction industry with schools and colleges making up a substantial amount of construction spending by the public sector in 2014; this equated to $£ 4$ billion and was exceeded only by the housing and infrastructure divisions (ONS, 2015). Moreover, the Education sector is facing the problem of school places as raised by the Department for Education and Skills (DfES, 2005) report stating that "only $14 \%$ of schools currently operate from buildings constructed since 1976. It is thought that the largest additional cost that the Education Funding Agency (EFA) will face is the accommodation of additional school pupils (Omigie, 2014). Disturbingly, it has been indicated that the current appraisals of $£ 12$ billion needed to address this shortage has been drastically underestimated and is likely to climb to $£ 18$ billion due to a combination of factors and not simply rising construction costs (Richardson, 2016; Fagent, 2016). One of the biggest contributors to this rise is that, in areas where demand is high, many of the easy to develop sites have already been completed, hence local authorities are tackling projects that are more challenging and undeniably more expensive (Richardson, 2016; Fagent, 2016). To worsen the situation, the government commonly has to purchase the land for new schools, paying market prices in urban areas where land costs are rising (Fagent, 2016; McMeeken, 2016). There is now an array of standardised solutions available on the market, claiming to reduce timescales and costs and improved quality when compared to bespoke alternatives. As a result of the current UK government's agenda to cut down the cost of school building projects, contractors are actively leading the delivery of standardised school designs (Geldard and Griffiths, 2011). Some of the standardised school design products available in the UK market are Sunesis (by Willmott Dixon), ADAPT (Wates), Kits of parts (Laing O'Rourke/Atkins), Pod Solve (Interserve) etc.

This paper examines the construction industry stakeholders' understanding of standardisation, drivers, benefits and challenges, and the measure of successful implementation of standardised schools in the UK in terms of cost, time and quality. The rest of the paper 
provides a review of relevant literature, a discussion of the adopted research methodology and the findings; discussions and conclusions are finally presented.

\section{Understanding the concept of standardisation}

The term "standard" can refer to a wide variety of scenarios varying from a unit of measurement (definitional), to a regular set of practices or even a way of looking at the world (Russell, 2005). Understanding standardisation is of vital importance because without clearly defined boundaries there may be misinterpretation and confusion leading to miscommunication of ideas and uninformed decisions. A prominent example of misperception relating to this area of research is the synonymous use within the construction industry of the terms "standardisation" and "pre-assembly" when it can be shown that these have clearly distinguished and differing definitions (Construction Excellence-CE, 2007). Additionally, the umbrella term has been applied to schools as demonstrated in the market availability of "standardised schools", in particular, two products at opposing ends of the scale are the "kit of parts" developed by Laing O'Rourke versus the modular building developed by Persimmons (Talbot and Francis, 2012).

Standardisation has been defined as "the extensive use of components, methods or processes in which there is regularity, repetition and a background of successful practice and predictability" (CE, 2007: 2) while the British Standard Institute (BSI) defines it as "something that provides for common and repeated use, rules, guidelines or characteristics for activities or their results, aimed at the achievement of the optimum degree of order in a given context" (BSI, 2011:6). Each of these definitions shares two fundamental ideas; firstly that standards need to be something that we can be repeated and secondly, that they are selected with the motivation of improvement. A key categorisation tool is to consider who has chosen the improvement outcome, this can vary from imposed national standards such as EU brick dimensions to project specific measures; for example on site quality assurance processes (CE, 2007). The use of Standardised processes and products has been used in construction for many years and remains an important part of the construction industry's best practice (Gibb and Isack, 2001). The use of standardisation in the construction industry can facilitates the drive to achieve lean construction (Polesie et al., 2009). 
Standardised school design offer efficient design that improves construction and provides cost certainty. There is also benefit to construction time from reduced leading time for components (Pasquire and Gibb, 2002). The adoption of the standardised school design approach (Livesey, 2012) for the Priority School Building Programme (PSBP) provided the UK government with greater certainty in cost, quality, time, and a good end-user experience. In order to reduce the cost of school projects, the procurement of the UK government's Priority Schools Building Programme (PSBP) is through the use of standardised designs (Pasquire and Gibb, 2002).

The standardisation process allows early involvement of the design team and suppliers to develop a set of standardised drawings and specifications (Tse et al., 2015). Again, James (2011) description of standardised school design means all new school buildings should be developed from a set of standardised drawings and specifications which should be improved continuously through the evaluation of lessons learned from project to project. However, CELE (2011:2) adds that standardised school design is mostly described in terms of "template" or "repeat" design which can be implemented with the aim of improving the efficiency of the building process. Adopting standardisation in school buildings does not mean the building structure will look the same; the designs can be custom-made to the needs of every client.

An agreed potential outcome of standardisation is the ability to encourage improvement and innovation, preventing "waste" in the construction industry (Russell, 2005). Design standardisation in particular has its own categorisation scale which denotes four distinct classifications for standardising design (Fox and Cockerham, 2000). The scale begins with 'bespoke solutions' which have no standardisation other than loose parts and materials followed by 'hybrid solutions' having standard sub-assemblies but bespoke interfaces. At the other end of the spectrum is 'custom designs', which have standard components up to assembly level and ultimately the most rigid form which is 'standard design' incorporating both standard components and connections (Fox and Cockerham, 2000). An alternative view to the understanding of how standardisation can be defined is commonly used in the manufacturing industry. This is known as the "volume versus variety" paradigm and essentially considers the trade-off between quantity and diversity of products available. Standardisation is described as fundamental neo-classical economic principle where learning and repetition leads to higher productivity (Sundbo, 2002). Standardisation is driven by 
stakeholders such as the government, local authorities, Manufacturers, Designers, Contractors and end-users. The "Pull Theory" introduced by Robinson et al. (2012) state that standardisation within the construction industry has a high dependency on its stakeholders because construction is essentially a service industry where buildings are designed and built to order. It promotes the importance of stakeholder engagement throughout the design process and defines this as a driving factor to success.

\section{The problem of primary school places and standardised school buildings}

The shortage of school places has reached unprecedented levels with over 30 thousand pupils in excess of their schools capacity and a quarter of a million new places needed over the next three years (ONS, 2015, EFA and DfE, 2016), equating to a $24 \%$ rise on the shortage over the past five years (Jeffreys, 2015). The school places deficit is becoming substantially worse with an expected quarter of a million new school places needed over the next three years (ONS, 2015) coupled with a $17 \%$ real term spending cut to government departments and rising construction costs (HM Government, 2011). The James Review (2011) into education capital was pivotal in the promotion of standardised solutions and although initially met with scepticism, has since shown to be fundamental in providing a catalyst for the development of standardisation. Recognising the need to reduce the deficit and address the school places shortage, the government in 2010 launched a comprehensive review of all capital investment projects funded by the DfE. The James review (2011) introduced a government initiative to move away from the expensive and inefficient Building Schools for the Future (BSF) scheme and promote "standardised design" for future UK school buildings (James, 2011). It is however important to note that the UK Government is also attempting to address the school

place shortage through the Big Society agenda which argue that, the state has become too big and therefore encourages civil society in the delivery of public services. The free school policy is demand-led and allows parents, teachers, faith groups and charities access to state resources in delivering quality schools in deprived communities (Higham, 2014).

The scheme the UK government is using to create additional school places is the adoption of the 'Priority Schools Building Programme (PSBP) (McMeeken, 2016). This scheme has proven to be much more efficient and much better value for money; claiming preconstruction time has been cut by half and costs by up to $40 \%$ (DfE et al., 2014). The benefits of utilising standardised design is immediately apparent with a speedy design process 
resulting in quicker tendering process (McMeeken, 2016) and drastic cost savings ranging from $30-40 \%$ (DfE et al., 2014).

The drive behind this strategy for the government is to ensure the contractor takes full responsibility for design risk (James and Brown, 2013). However this raises questions over how much design development can take place before a project is no longer "standardised" and who should make these decisions. Considering its mass production aspirations and reacting to market forces, contractors rather than architects have shown themselves to be leading the execution of standardised school buildings with companies producing competing standardised school models for the education market (Geldard and Griffiths, 2011). The UK government has had a big impact on driving standardisation within the construction industry and promisingly architects and contractors have invested hundreds of thousands of pounds in developing designs and building systems that will enable cost-effective and efficient construction of schools on a large scale (Richardson, 2016). However the recent "Baseline Guidance" specifying that schools "should be simple rectilinear forms and built for $£ 1,465$ per square metre (half the price of most BSFs)" (Gardiner, 2015) requires some of these contractors to revise their designs; with an unwelcome expense. This rigidity impedes efforts by individual firms to find a solution and questions whose responsibility it should be to drive and monitor the success of implementing standardisation. Fargent (2016) believes that, for the government to continue to see the results it desires from implementation of standardisation, it will need to follow the Government Construction Strategy (2011) advice in becoming an intelligent client by developing the art of standardised bulk procurement of schools, potentially driving direct relationships with material suppliers as well as building contractors. To add to the above, Boothman et al. (2014) research examining stakeholders view on the delivery of school buildings using off- site construction noted that, the involvement of the stakeholders in school projects is essential in achieving value for money and reducing defects in a successful project.

\section{Benefits and challenges to the adoption of standardised Schools}

In a study by Linner and Bock (2012) on the evolution of large-scale industrialisation and service innovation in Japanese prefabrication industry, it was noted that the industry is not just delivering standardised or prefabricated building products but more importantly focusing on the provision of services relevant to the operational/in-use stage. The UK construction 
industry could learn from the above by considering the delivering of standardised schools that does not just concentrate on the capital project cost only but also the impact on end-users at the post-occupancy stage (Linner and Bock, 2012).

The overarching benefit asserted by standardisation is a reduction in cost (Gibb and Isack, 2001; James, 2011; James and Brown, 2013). A notion which has been developed from Adam Smith's theory; that increasing returns results from division of the workforce (Smith, 1977)commonly known as 'economies of scale' suggests that, the more of something you do, the more efficient you become at doing it and so less input will be required for the same or an increased output (Smith, 1977). In construction, capital cost savings arise due to the inherent simplicity and efficiencies in the design approach taken to standardised solutions, combined with the more limited availability of options leading to a reduction in design fees while making bulk purchase discounts viable (Talbot and Francis, 2012; CE, 2007).

Standardisation is considered as a means of reducing variation in product quality which results in cost savings by reducing uncertainty while also saving the time and efforts consumers spend on searching (Gibb and Isack, 2001). One of the key theoretical foundations explaining this phenomenon was the "Transaction Cost theory" first introduced by Coase (1937) and further developed by Williamson (1975 and 1989). Transaction costs are brought about by the opportunistic behaviour of stakeholders to the contract and are influenced by three characteristics; asset specificity, frequency and uncertainty surrounding the transaction. Interestingly, cost savings resulting from standardisation have been exploited heavily in sectors such as retail and leisure (Covell, 2012). Another consideration is that standardised solutions claim to have "in-built" sustainability. It is not clear how this is effectively incorporated in practice since the most significant contribution is from a school utility bill perspective (Talbot and Francis, 2012). Standardised schools designs should be robust, fit for purpose with low maintenance and running costs; also end-user involvement is key in the delivery of such projects.

Time is intrinsically the second most prominent benefit of standardisation and a major component in assessing the success of a construction project. This has been substantially agreed upon by both the construction industry and other sectors (James 2011; Covell, 2012; Talbot and Francis, 2012). Time needs to be considered at various stages in a project such as procurement, design and the construction phases of a programme. Procurement time is a key consideration for any client, but in particular for the public sector (HM Government 2011; Gardiner, 2012). The availability of frameworks for these public sector bodies, such as Scape Framework (2016) and the Southern Construction Framework-SCF (2016) provide 
dramatically reduced procurement timescales. For example the Scape framework claims 20 weeks savings on projects over $£ 5$ million. Salama et al. (2006) argue that the size of a project does not affect the contractor's overheads significantly when bidding for standardised designed schools. Additionally, by reducing the number of competitors bidding for frameworks contracts, many of the transactions costs associated with contracting the works are removed (Talbot and Francis, 2012).

A major contributor to the headline time savings is as a result of utilising pre-assembly with the benefits of increased efficiency and speed (CE, 2007), in addition to reduced design time (Talbot and Francis, 2012). These benefits will heavily depend on what concurrent construction methods are being used on site and whether the pre-assembled items impact on the critical path. Unless a contractor has large stock of complete parts in storage, preassembly may lead to the problem of storage, especially when moving towards volumetric and modular categorisations. Another disadvantage of standardised designs is that, design decisions generally will have to be made earlier than for conventional construction, and critical information needs to be established sooner. The 2011 Construction Strategy reported that for the public sector to embrace the advantages of innovative processes such as standardisation, it must become an 'intelligent client' and reward the industry by considering planning application for schools as a priority, working with the industry to help move schemes forwards rather than creating roadblocks (HM Government, 2011; Gardiner, 2012; James and Brown, 2013).

Quality is stated as a key benefit of standardization closely followed by time and cost; whereas time and cost have (at least on the surface) very measureable scales upon which to pass judgement, quality is 'in the eye of the beholder' and purely based on perceptions (Gibb, 2001). Quality is also deemed to be a contributory factor when considering value for money hence it is thought that consistent quality is fundamental to client satisfaction (Gibb and Isack, 2001). Pre-assembly benefits are thought to impact directly on the number of defects and amount of rework required (directly impacting on both cost and time). One of the key considerations to maximise the benefit of pre-assembly and off site fabrication is to utilise it for the purpose of minimising the number of trade interfaces, this will allow for improved buildability and a reduction in time spend snagging since a level of quality check will already have been conducted (Gibb and Isack, 2003).

A major contributor to this success is the ability to undertake the process of continuous learning utilising 'lessons learned' from project to project to continually develop and improve 
design (Covell, 2012; James and Brown, 2013). Additionally, standardisation leads to improvement through a shortening of the learning curve (Edum-Fotwe et al., 2004); reducing training requirements at two distinct phases; firstly, for the operatives undertaking the construction and secondly, for the customers using the end product (Gibb and Isack, 2001; Covell, 2012). This being said, there are fears that "off-the-shelf" designs can result in less innovation (Robinson et al., 2012), resulting from a stable and unchanging system (Kondo, 2000). Social and environmental benefits of pre-assembly are the consequence of bringing the construction site into the factory; here the environment can be controlled to create a safer, healthier and less wasteful working environment (CE, 2007). It is noted that the maximum benefits arise when standardisation and pre-assembly techniques are applied together (CE, 2007; Gibb, 2001). In practise however it can be seen that the benefits are rarely specifically measured, but instead based on client or project perception (Gibb, 2001). A crucial discovery is the under-representation of disadvantages of standardisation in the literature. It seems as though an imbalanced argument for its use exists promoting benefits for the instantaneous results and neglecting the potential long term negative impacts that are possible.

\section{Research Methodology}

Even though standardisation is well established in the manufacturing industry, it's relatively less explored when considered in a construction context. A pragmatic research philosophy is identified as the most appropriate for this study since the phenomena under investigation is subjective in meaning and understanding (Creswell, 2009; Saunders et al., 2012). The study therefore adopts a mixed method approach to address such an important social issue as the shortage of school places to provide diverse theoretical positions. The additional use of data triangulation allows the researcher to overcome weakness or intrinsic biases present in selecting just one form of data collection method (Knight and Ruddock, 2008). The first round of primary data collection is quantitative with a goal of uncovering relationships between variables (Saunders et al., 2012). This was followed by semi-structured interviews with the intention of both validating the survey results and justifying meaningful conclusions (Knight and Ruddock, 2008; Robson, 2011). The relevant population for this study is the construction industry professionals/stakeholders in the UK with experience in educational sector building projects. A large sample size is required for quantitative research to allow reliable statistical analysis and non-probability sampling using a snowball method is used. However, a purposive sampling was utilised for the qualitative data collection to allow the selection of interviewees based on their experience in delivering school projects and expertise 
in standardised school construction. Due to the volume of data collected, SPSS Statistical software was used to help in conducting econometric analysis of the data. However, data from the semi-structured interviews were transcribed and interpreted using content analysis (Creswell, 2009).

\section{Quantitative data collection and analysis}

The questionnaire was distributed to 500 construction professionals/stakeholders involved in delivering school projects in the educational sector in the UK, covering a variety of disciplines, 306 questionnaires were returned providing a response rate of $61 \%$; this is comparatively high signifying a well-designed survey. Data analysis was carried out to understand the research participants who took part in study by categorising responses both by demographic and discipline. As can be seen by the two pie charts in Figure 1a \& 1b, for both of these figures, there is a substantial variety within the respondents, providing increased confidence with results since this indicates less chance of bias. As much as $50 \%$ of respondents are main contractors while $22 \%$ are from the subcontractor background working on education projects. . In terms of respondents' discipline, $34 \%$ are professionals from the commercial sector with $20 \%$ from the operations/planning discipline.

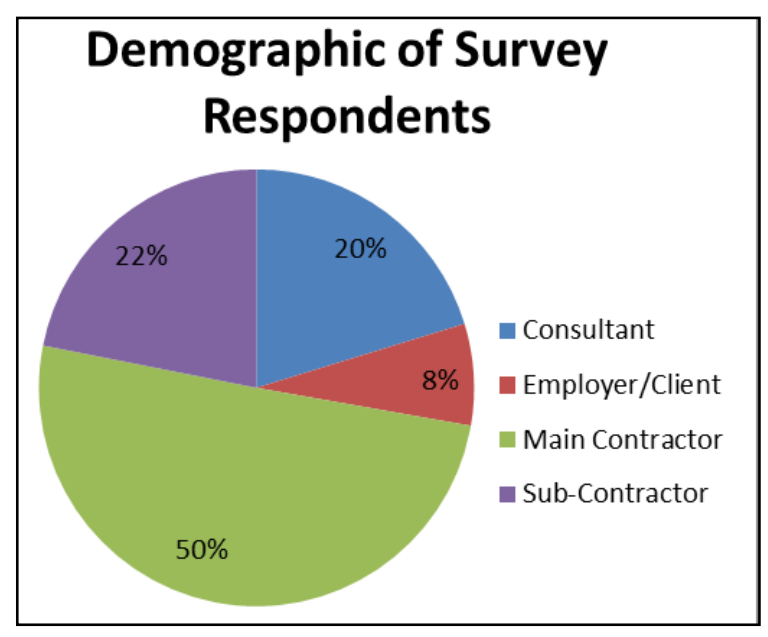

Figure 1a: Respondents' Demographic

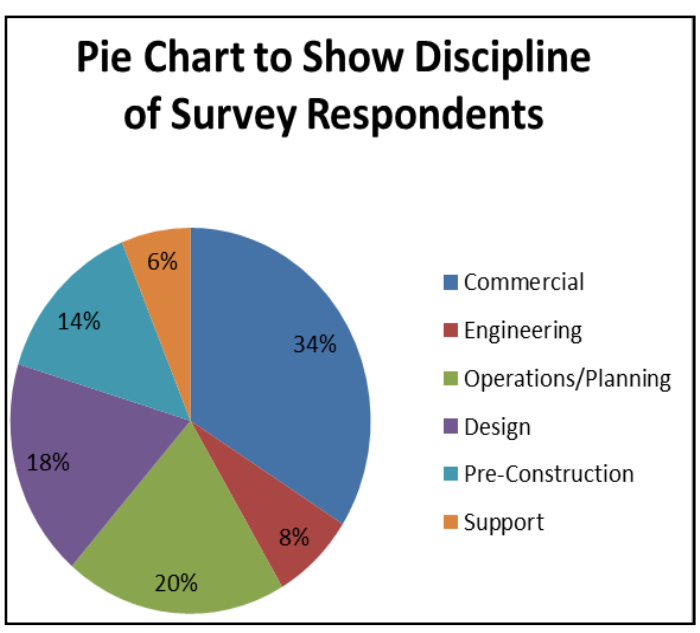

Figure 1b: Respondents' Discipline

\section{Construction industry stakeholders understanding of standardisation}

To establish respondents' understanding of standardisation, a series of five statements are presented from literature review and participants are asked to select the level to which they agree or disagree using a 6-point Likert scale with no neutral value. 
This is a discrete data collection method obtaining ordinal data, which is data that has a clear order but the distance between values is undefined. For example, the distance between 'slightly agree' and 'agree' may not be equal to the distance between 'agree' and 'strongly agree'. For this reason the most suitable analysis is utilising descriptive statistics, in particular the modal value (measuring the most frequent), this is a measure for central tendency along with median or mean values (Hoxley, 2016). To specifically address the central tendency bias, a combination of methods have been utilised to combine total "agree values" and compared these against all "disagree values" (for example, "statement A agree value is $42+185+70=297$ and disagree value is $1+3+5=9$ ); the result is presented in Figure 2 . Although the modal value for "disagree" is at $30 \%$, the results highlights that, the difference between total "agree" versus "disagree" of just $12 \%$ is too small to have any confidence in the response. However for statements A, B, D and E, confidence is improved with the number of "agree" responses are at least $40 \%$ higher than "disagree".

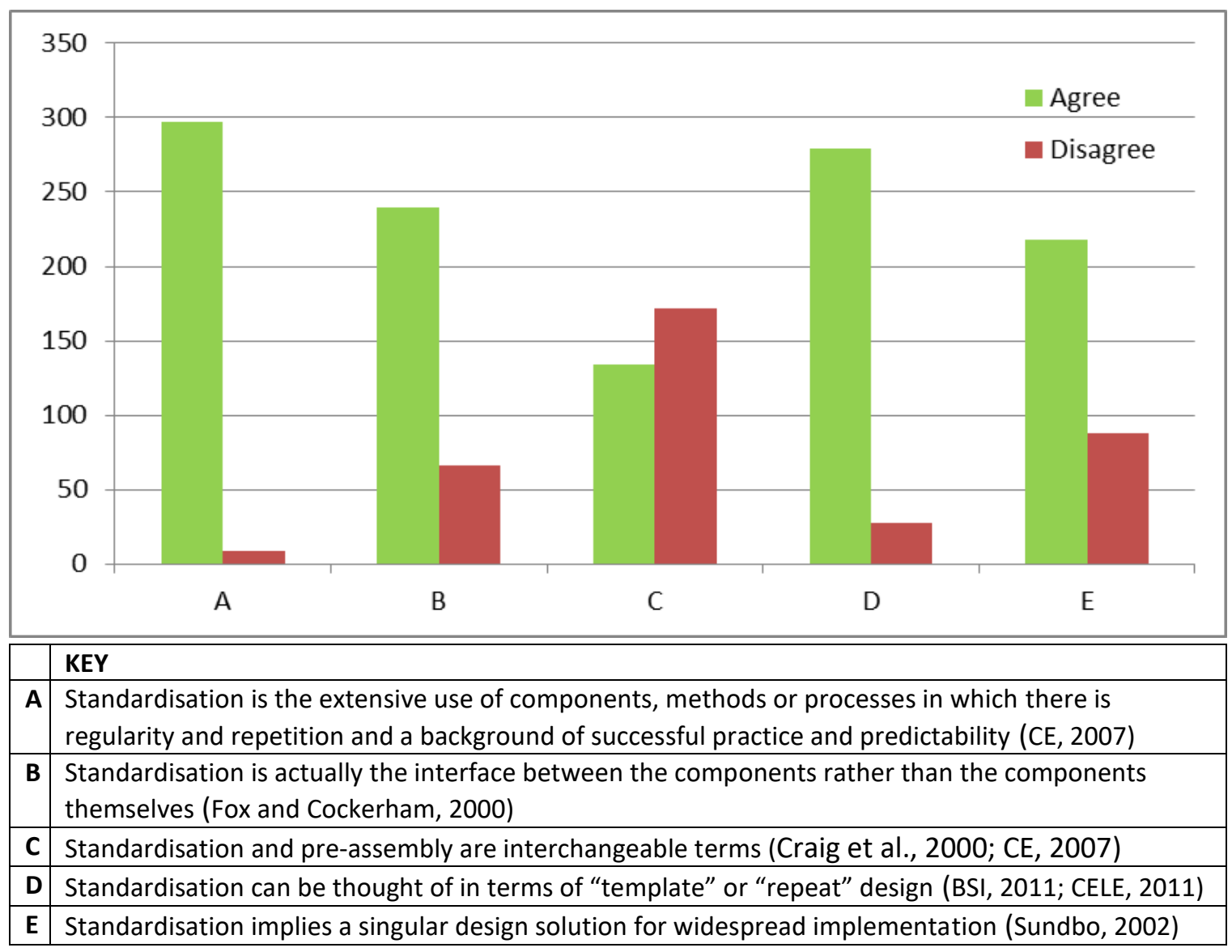

Figure 2: Level of respondents understanding of standardisation 
The respondents were asked to rank the influence of the key stakeholders involved in the adoption of standardisation when delivering schools, and the results show that, Designers are the most influential stakeholder with statistical mean of 5.04, followed by Contractor (4.91), Clients (4.71), Central Government/Local Authority (4.17) and Manufacturers with a mean of 4.11. The results clearly show that 'Academic and Research Institutions' and 'professional bodies are the lowest ranked stakeholders with a mean value of 2.67 and 2.39 respectively as illustrated in Figure 3. This result demonstrates that, these stakeholders have little influence in driving standardisation in the delivery of school projects.

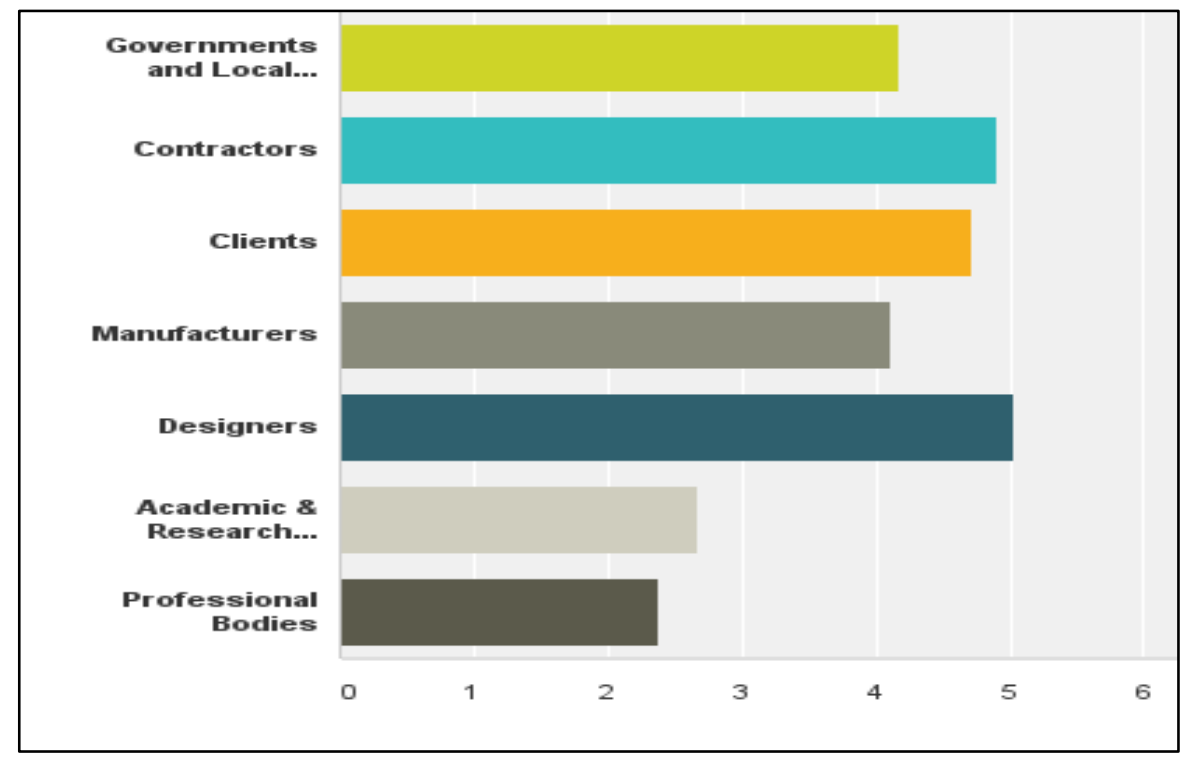

Figure 3: Stakeholder influence on delivering standardised school buildings

The three highest ranked stakeholders are 'designers', 'contractors' and 'clients', however the difference appears to be minor so statistical testing (Friedman Test) was carried out to distinguish whether or not these differences are significant. The Friedman Test is a nonparametric test from the chi-squared family which works by comparing the mean ranks between the related groups and indicates how much these groups (stakeholders) differ and if this is statistically significant. The test has been conducted for the top three stakeholders only; 'designers', 'contractors' and 'clients'. Friedman Test result: $\left(\chi^{2}\right)=(2)=4.078, \mathrm{p}=$ 0.13 ( $p>0.05$ hence not significant) is presented in Table 1. It shows that there is no statistically significant difference between the top three drivers of standardised school designs. Although this test has failed to show a significant difference, it does not mean that a difference does not exist; it simple means that the difference may be too small for this test to detect it. 


\begin{tabular}{|l|l|r|l|}
\hline Test Statistics $^{\text {a }}$ & \multicolumn{2}{|c|}{ Ranks } \\
\hline $\mathrm{N}$ & 306 & Contractors & 2.03 \\
\hline Chi-Square & 4.078 & Clients & 2.07 \\
\hline df & 2 & Designers & 1.91 \\
\hline Asymp. Sig. (2-tailed) & 0.130 & rivank \\
\hline
\end{tabular}

Table 1: Friedman Statistical Test for Top three Drivers of Standardisation

\section{Benefits and challenges of standardised Schools}

Respondents were asked to rate the top three most influential benefits and challenges of standardisation from a selection of ten options identified in literature. The results are illustrated graphically in Figures 4 and 5 respectively. The most influential benefit of standardisation according to the findings is "reduced construction programme" (49\%) closely followed by "reduced defects" (47\%) with "reduced construction costs" and "reduced waste" $(38 \%)$ sharing third position. The chosen benefits, generally speaking fit into the measurement criteria of time, cost and quality showing an agreement with earlier findings. When considering the challenges however, the most frequently selected options are "reduced design flexibility" (65\%) and "limited product choice" (53\%) which are more concerned with the process of standardisation rather than the outcomes. Additionally, these were the most represented challenges identified from the literature review providing confidence in their significance.

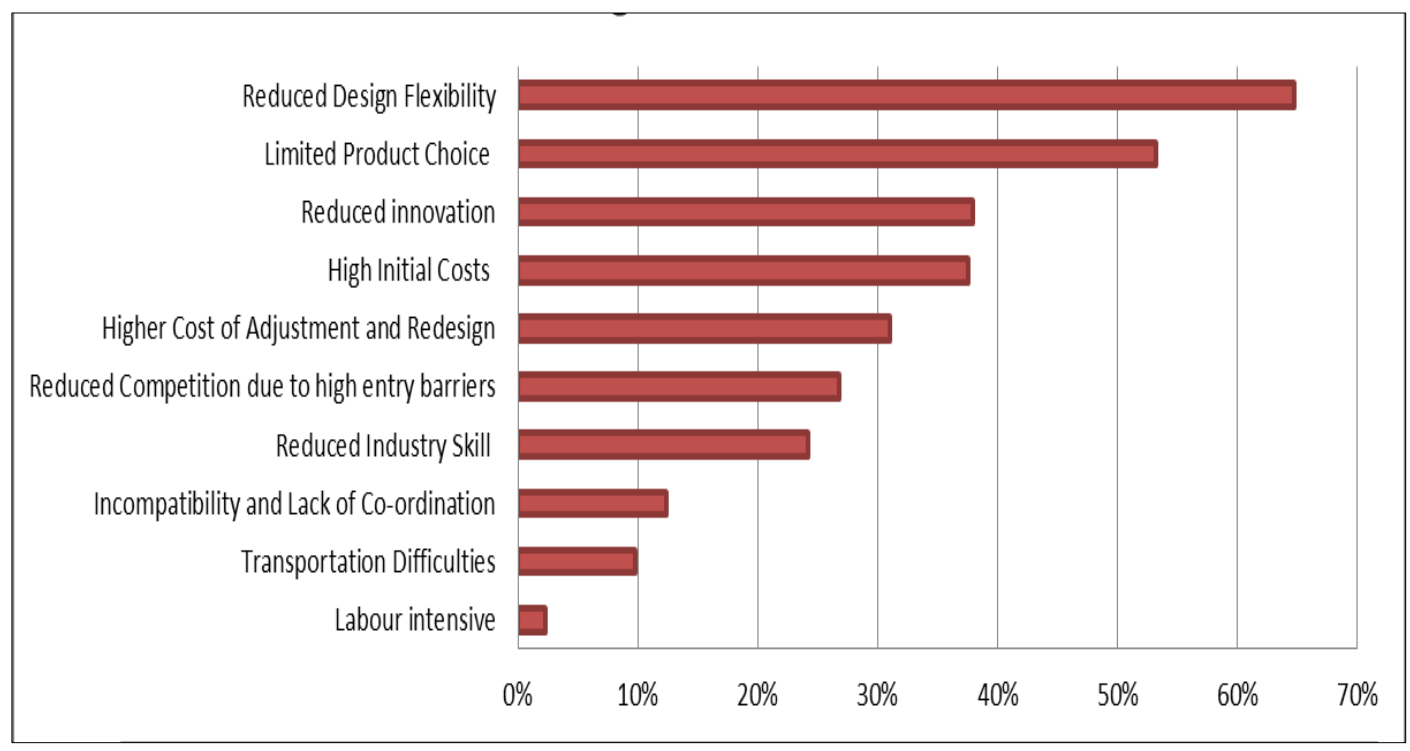

Figure 4: Most influential benefit of standardisation 


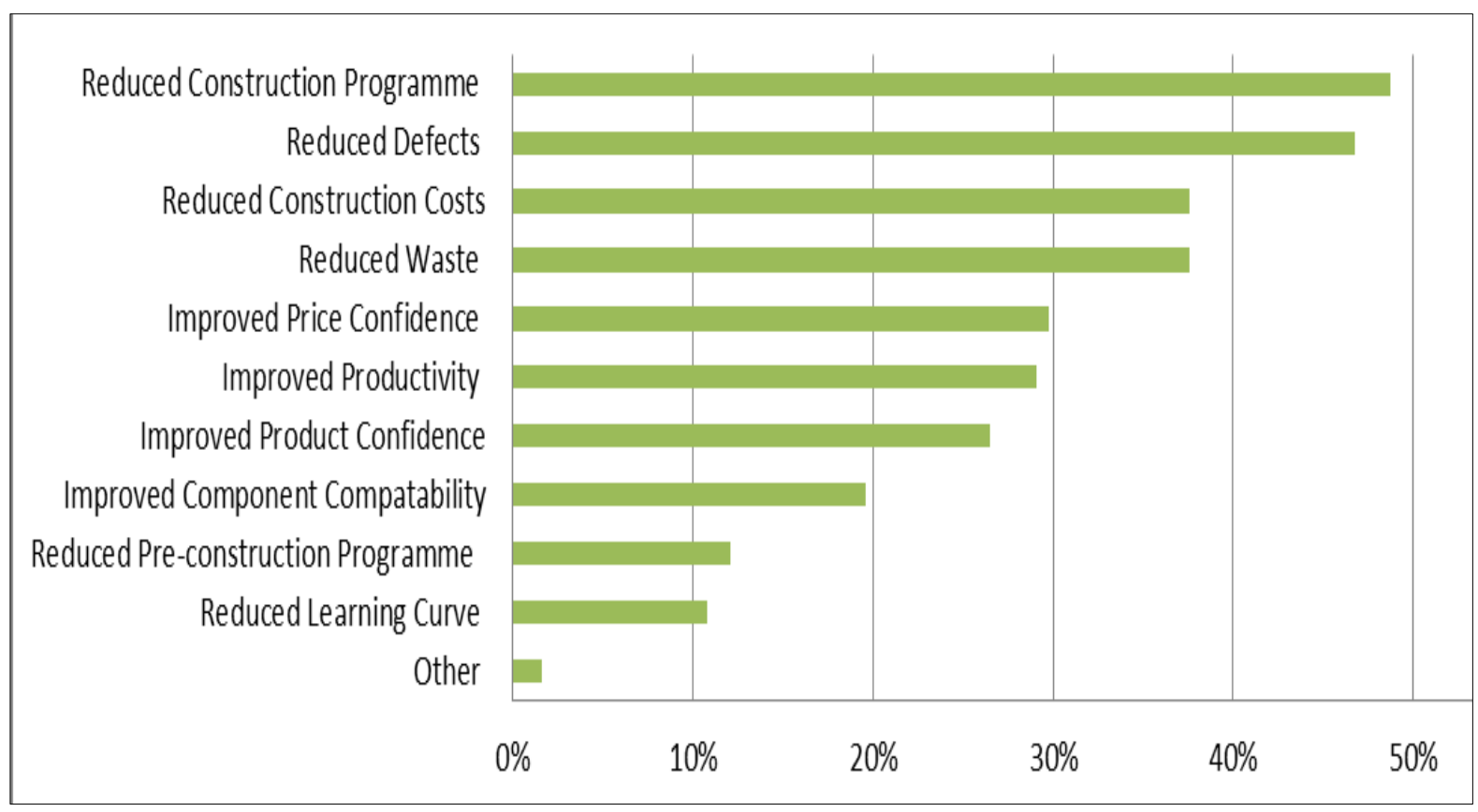

Figure 5: Main Challenges of standardisation

\section{Measuring the successful implementation of standardised schools}

To measure the successful implementation of standardised school designs in terms of time, cost and quality, respondents were asked to select the best and worst indicators of success identified through literature review. The results are presented in Figures $6 \mathrm{a}, 6 \mathrm{~b}$ and $6 \mathrm{c}$. Due to the polar nature of data collected, a weighted value has been calculated by assigning "best measure" responses a ' +1 ' value and "worse measure" responses a '-1' value providing an overall "weighted value". This manipulation of the figures provides a check for consistency and patterns amongst data; for example, considering the first chart for time, the best and worst measures have minimal conflicting results, whereas the other six options have weighted values closer to zero indicating disagreement amongst their use as a measure. An interesting observation is shown for "cost per square meter" where 39 respondents chose this as the best measure (making it 3rd best) but 50 respondents chose this factor as the worst measure (making it 2nd worst); this highlights a diverse views in the construction industry. It is clear to see that for each case, an apparent leader emerges, namely "overall project duration" for time, "whole life/life cycle costs" for cost and finally "reduced defects and rework" for quality. Alternatively, "planning approval duration", "total consultant costs" and "BREEAM certification" were chosen as the least important measure of time, cost and quality respectively. 


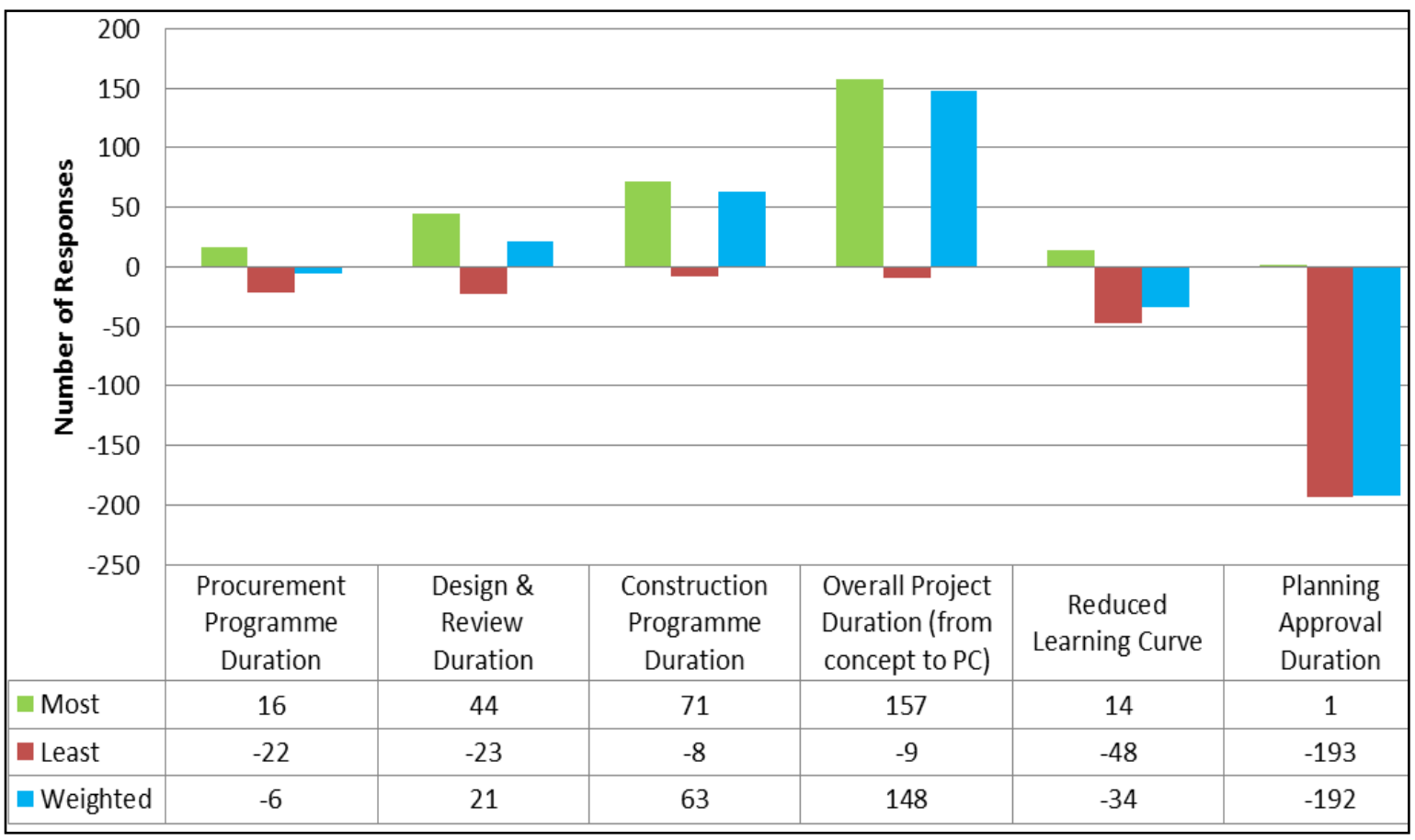

Figure 6a: Measure of standardisation success in terms of Time

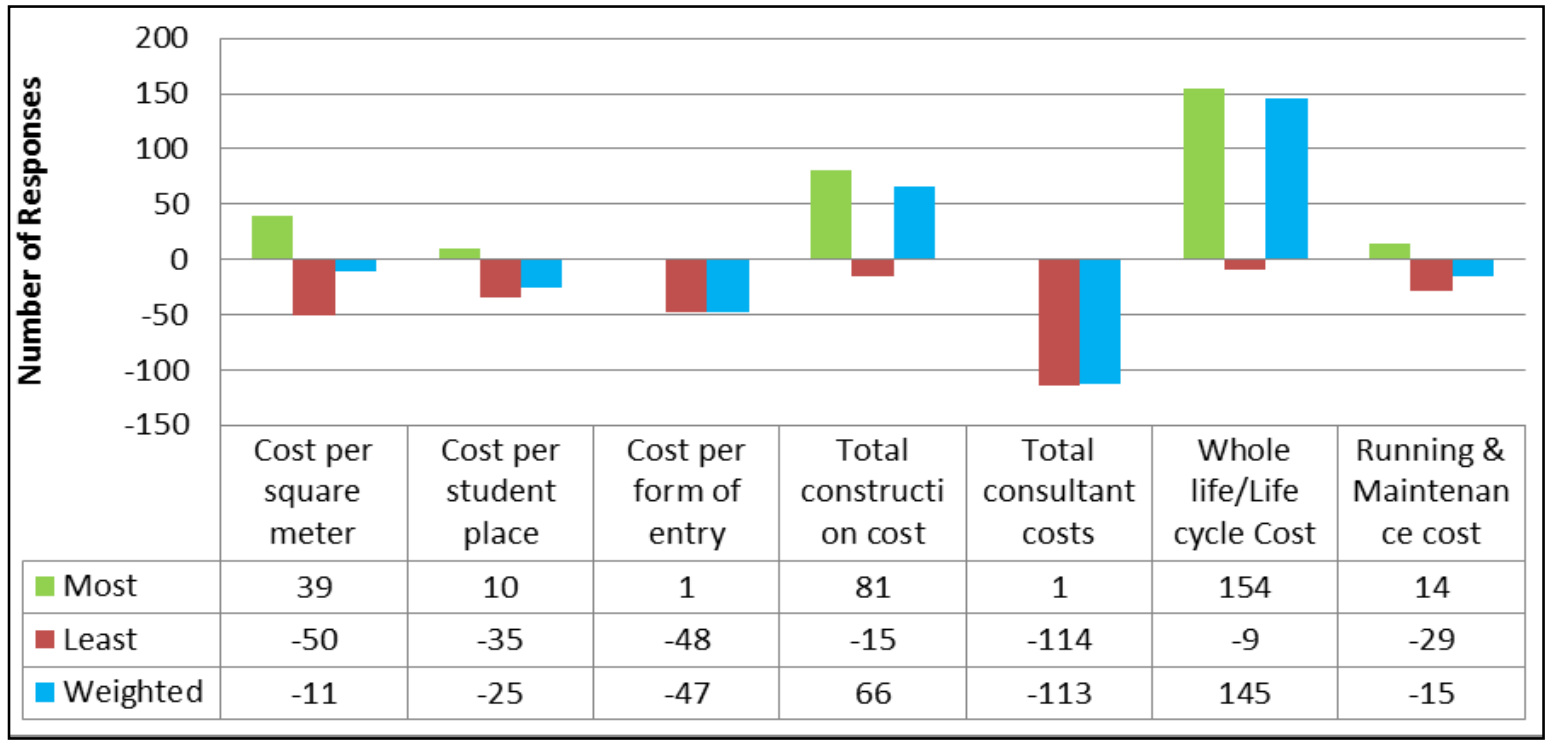

Figure 6b: Measure of standardisation success in terms of Cost 


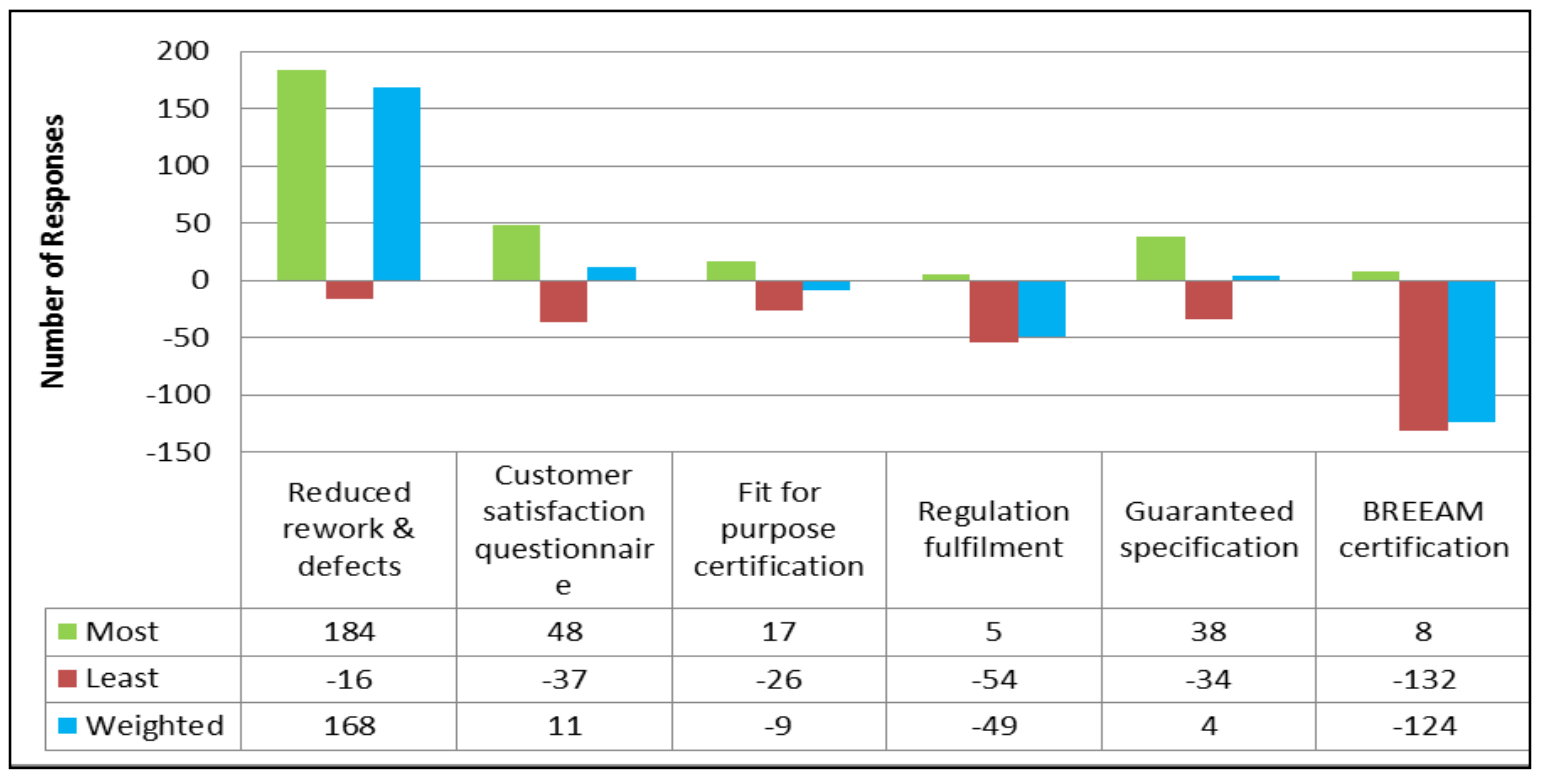

Figure 6c: Measure of standardisation success in terms of Quality

\section{Qualitative data collection and analysis}

Qualitative data was collected through semi-structured interviews with a range of industry professionals/stakeholders as summarised in Table 2. Purposive sampling was used in selecting the interviewees based on their expertise and experience. Each interviewee was issued with the questions ahead of time to allow them to feel confident in their ability to engage fully with the interview process. The interviews varied from 30-40 minutes in length, they were recorded and transcribed and then checked by the interviewees to confirm accuracy and validity of responses (Opoku et al., 2016). The process of transcribing interviews was completed personally by the researcher rather than utilising software, this was a laborious and time-consuming process but enhanced the researcher's ability to identify common themes and patterns for later coding. Qualitative coding was used to organise the raw contextual data which is highly unstructured. The design of the interview meant that all interviewees were asked the same questions which were then open to interpretation. 


\begin{tabular}{|l|l|l|c|l|l|}
\hline Ref. & Job Title & $\begin{array}{l}\text { Project } \\
\text { stakeholders }\end{array}$ & $\begin{array}{l}\text { Years } \\
\text { of exp. }\end{array}$ & Background information & $\begin{array}{l}\text { Interview } \\
\text { of method }\end{array}$ \\
\hline A & $\begin{array}{l}\text { Associate } \\
\text { Architect }\end{array}$ & Consultant & 13 & Specialises in designing schools & Face-to-face \\
\hline B & $\begin{array}{l}\text { Associate } \\
\text { Architect }\end{array}$ & Consultant & 8 & $\begin{array}{l}\text { Specialises in designing } \\
\text { standardised schools }\end{array}$ & Face-to-face \\
\hline C & $\begin{array}{l}\text { Structural } \\
\text { Engineer }\end{array}$ & Manufacturer & 16 & $\begin{array}{l}\text { Specialises in designing } \\
\text { standardised steel frames schools }\end{array}$ & Telephone \\
\hline D & $\begin{array}{l}\text { Design } \\
\text { Manager }\end{array}$ & Contractor & 13 & $\begin{array}{l}\text { Manages design for all types of } \\
\text { education construction including } \\
\text { standardised options }\end{array}$ & Face-to-face \\
\hline F & $\begin{array}{l}\text { Product } \\
\text { Director }\end{array}$ & Contractor & 15 & $\begin{array}{l}\text { Innovation and development of } \\
\text { standardised schools }\end{array}$ & Face-to-face \\
\hline G & $\begin{array}{l}\text { Project } \\
\text { Manager }\end{array}$ & $\begin{array}{l}\text { Client ( Local } \\
\text { Authority) }\end{array}$ & 30 & $\begin{array}{l}\text { Procurement and management of } \\
\text { new built school projects }\end{array}$ & Face-to-face \\
\hline H & $\begin{array}{l}\text { Design } \\
\text { Manager }\end{array}$ & Manufacturer & 30 & $\begin{array}{l}\text { Design, manufacture and } \\
\text { installation of pre-assembled } \\
\text { modular classrooms }\end{array}$ & Telephone \\
\hline I & $\begin{array}{l}\text { Procurement } \\
\text { Manager }\end{array}$ & $\begin{array}{l}\text { Client ( Local } \\
\text { Authority) }\end{array}$ & 27 & $\begin{array}{l}\text { Procurement and management of } \\
\text { education projects }\end{array}$ & Face-to-face \\
\hline
\end{tabular}

Table 2: Profile of Interviewees

\section{Understanding standardisation}

The interviews demonstrated that a variety of accepted definitions are understood within the construction industry with many respondents accepting multiple definitions while emphasising their view that it is a difficult concept to define. In particular it is common for interviewees to define standardisation by how they feel others perceive it, such as through the eyes of the customers the interviewees work with. Additionally many chose to describe standardisation through its limitations or appearances.

For example interviewee 'H' explains that; "To me standardisation would be using the same processes, products and knowledge to gain a defined result". However, interviewee 'A' added that, "My understanding of standardisation is, offering a solution with limited options to ensure that speed/timing and cost are all gained through". 
“My understanding of standardisation is a 'standard package' of the build with restrictions in terms of what you can do,....more of what I call an "Ikea school" (Interviewee F). Although this is a narrow view in comparison with the definitions that have been uncovered by the literature review it highlights how an end user and those involved with implementing standardisation perceive it. According to interviewee 'D', "standardisation is about operating and refining repeatable sets of processes as well as repeatable design". If the sentiment of the answers are considered (how positive or negative they are) it is shown that the majority of answers provided are neutral with some positive sentiments but minimal negative coding found.

\section{Benefits and challenges of standardised schools}

Content analysis was conducted on the responses to the question of benefits and challenges of standardisation. The results highlight that, an almost balanced argument has been presented for positive compared to negative opinions. The benefit of reduced construction time and cost is evident in the results analysis. For example interviewee 'A' said that, "The benefit knocks onto everything, it would benefit cost, it would benefit time, and it would improve on defects and quality". Interviewee 'F' however added that, "I think the speed at which it can be constructed and go up, that is probably the biggest benefit. Also it's a tried and tested model over a short period of time".

The benefit of repetition and lesson learned associated with the use of standardisation is highlighted in a comment by the Design Manager; "The biggest benefit of standardisation is probably being able to learn from previous mistakes and to have a benchmark against which you can improve (Interviewee D). This notion is further emphasised by interviewee ' $\mathrm{B}$ ' describing the level of certainty standardisation offers. "I think it offers a degree of certainty, for it to become a standardised component. Standardised design or standardised layout you'd like to think that you know what you're getting both now and going forwards" (Interviewee B). However, The overarching theme present in the benefits however is a warning against over-reliance on these outcomes, phrases such as "if used correctly" (Interviewee D) and "If you do it right" (Interviewee E) preceded stated benefits alluding to occurrences of benefits not being achieved.

In terms of the disadvantages/challenges of standardisation, a high portion of responses were mixed, highlighting the complexity of this topic. In particular it was surprising to find that the concept of disadvantages of standardisation was not simply answered but instead challenged: 
"I don't think there is a disadvantage, I think there is a perceived disadvantage in the fact that it's not marketed right, we don't have the evidence to convince people to go with it" (Interviewee E). This outlook was not unique and was further justified by Interviewee 'I' with the use of a car analogy; "I don't think there are disadvantages; there are challenges in getting people to buy into the standardised product. People have their own unique preferences, so you have the challenge of getting buy-in to that standard solution" (Interviewee 'I').

\section{Measuring the successful implementation of standardised schools}

The interviewees were asked to identify the best measure of successful implementation of standardisation. It was immediately evident that respondents chose not to directly answer this question, choosing instead to provide an array of possibilities for how success is measured and justifying the suitability of each. For example, interviewee ' $\mathrm{H}$ ' argues that "The success of standardisation is a difficult one to measure because everybody measures it in a different way. Some measure it on cost, other measure it on reduced programme time, but I think it's the end quality that standardisation has the biggest impact on".

The overarching theme of the balance between time, cost and quality was noticeably present with almost all respondents either directly or indirectly mentioning them. Interviewee 'E' therefore commented that, "In reality, the proper answer is that it's really a combination of the best compromise between price, time and quality. But achieving that is a very difficult thing to quantify". When specifically considering cost, emphasis was placed on the importance of whole life costing as opposed to the more commonly used cost per square meter measure. "Whole life cost is a very good measure, as a technologist, it's good to see the cause and effect and I don't think even now as an industry, we realise doing certain things and their effect for the whole life of a building" (Interviewee A).

An additional theme that was prominent in the interview responses was the measurement not of items or processes but of the "impact" that buildings have or that standardisation has on buildings. Furthermore, the impact on the end users was discussed including the influence it can have on education delivered and on those who run and maintain the premises. For example interviewee 'D' highlighted that, "Standardisation done successfully is where the client is satisfied with the end product and that the net building cost is low by reducing the amount of time to design and build by using repeatable specifications at the same level of quality". 


\section{Discussions and interpretations}

The study uncovered a vast array of definitions of standardisation but two fundamental ideas can be identified; firstly, that standards need to be something that can be repeated and secondly, that they are selected with the motivation of improvement. This notion was tested during the quantitative round of data collection by asking respondents to rate the level of agreement or disagreement with the statement, "Standardisation is the extensive use of components, methods or processes in which there is regularity and repetition and a background of successful practise and predictability". An overwhelming majority of 97\% agreed with this (more than any of the alternative definitions proposed). Additionally, these two notions of repeatability and improvement were frequently cited during the qualitative data collection. This gives confidence in accepting these two concepts as the fundamental foundations upon which a more comprehensive definition for standardisation can be developed. The questionnaire highlighted a level of confusion amongst industry professionals/stakeholders with over $70 \%$ agreeing with the following two statements "the most important area for standardisation is actually the interfaces between the components rather than the components themselves" and "standardisation implies a singular design solution for widespread implementation". However the statements contradict each other in the sense that one promotes a single solution and the other promotes multiple solutions. This sentiment was mirrored during the interview process with a variety of interpretations posed, however interviewees 'B', 'E', 'F' and 'I' all remarked that a variety of definitions exist and that not everybody truly understands it.

A particular area for confusion was the synonymous use within the construction industry of the terms "standardisation" and "pre-assembly". When this phenomena was tested during the quantitative data collection reinforcing the divide amongst the industry with $44 \%$ agreeing that the terms are used interchangeable. This confusion was reflected during the interviews with many describing their understanding by conveying the limitations and restrictions standardisation holds. A suggestion for this is that only parts of the process are seen or considered and instead a scale similar to that of pre-assembly needs to be developed and circulated within the industry to allow for a better understanding of potentially improved perception and uptake of standardisation. Further investigation is required into its understanding in relation to the construction industry; specifically in order to establish how best to utilise its benefits for all stakeholders. Once a unified definition/meaning is 
established, relevant measures need to be agreed for time, cost and quality attributes of standardisation.

The questionnaire asked participants to choose the three most influential benefits and challenges from ten options identified in literature. The results show that, "reduced construction programme" is the most influential benefit of standardisation. Interviewees supported this notion with some specifically promoting programme benefits (Interviewees B, F and G), while others endorsed learning and efficiency (Interviewees A, E, F and G) as the best benefit of standardisation. However, a conflicting view was posed by interviewee 'I' who argued that since schools have no commercial opportunity for creating income, delivering a school early has no advantage and may even be a disadvantage since it will require maintenance from the point of handover. Hence, it could be argued that the benefit of time lies in confidence and consistency to complete something for an expected date (September for schools) and not necessarily speed. From the interviews, the three key-words identified when discussing the challenge of standardisation were 'limitations' (A, F, H), 'inflexibility' (B, E, G) and 'perception' (B, D, E); this reinforces the top two challenges stated in the survey as 'reduced design flexibility' and 'limited product choice'. Another interesting perspective was introduced by interviewee ' $I$ ' who stated that there is 'no disadvantages but challenges'; an opinion which could explain the lack of discussions on the disadvantage presently in literature.

The fundamental recommendation for utilising standardisation is underpinned by the neoclassical economic principle that repetition leads to enhanced learning and hence higher productivity. This justification has been applied to the construction industry's drive to explore standardisation to realise substantial savings of both time and cost while seeking to improve quality. The government frequently sets targets for desired cost per square meter rates of schools which may be an oversight since it promotes immediate savings at the exchange of long term value. Life cycle costing was voted the best measure for cost during the questionnaire and this was supported by interviewees providing examples of 'cause and effect' considerations of life cycle costing. The second major area deemed essential for measuring improvement is reducing timescales, the questionnaire highlighted that this needs to be from a comprehensive perspective, minimising time required for the overall project duration from concept stage to practical completion. The largest emphasis for measurement has been on quality which has been re-iterated in many forms such as reducing rework and 
defects (ranked first in the questionnaire) or in a more subjective light by considering client satisfaction. This was discussed in greater depth during the interviews by focusing on client feedback over the life of a building, to measure both robustness and functionality. Many agreed that it is difficult to accurately quantify the success of standardisation and in particular that a focus needs to be on long term measurement of success such as the use of whole life costing and client feedback over the life of a building to measure both robustness and functionality.

\section{Conclusions}

Standardised school design is a major contributor to the government's plans for addressing the UK's shortage of school places under the Priority School Building Programme (PSBP). There is now an array of standardised solutions available on the UK market aimed at reducing time, costs and improved quality when compared to bespoke alternatives.

The study revealed that the level of knowledge that construction professionals have on this subject is incomplete, leading to assumptions that are incorrect, and a poor perception of standardisation generally. A more holistic view is therefore required to provide a suite of definitions on what constitutes standardisation. The study however defines Standardisation as the extensive use of components, methods or processes in which there is regularity and repetition and a background of successful practise and predictability.

The literature review identified an imbalance in the existing body of knowledge to discuss the benefits of standardisation more readily than the disadvantages. It was surmised that this may be because those who fund or commission research into standardisation do so with an aim of promoting its use because they may have something to gain.

The notably benefits identified in the study were very similar to the uncovered measures indicating that these benefits are so highly regarded because they are something that the industry can "see"; monitor and compare it to provide evidence of progress. Unfortunately these benefits therefore come with the same warning that must be applied to the measures used to judge them, since they only provide a snapshot in time and circumstance, caution must be taken against their use and thought needs to be given to the more subjective attributes, such as learning and true customer satisfaction which are less easy to establish and quantify. 
Interestingly the top three voted challenges of standardisation are all subjective answers considering choice, flexibility and innovation. This was reinforced by the interview round of data collection, further confirming that challenges are centred on subjectivity and perception. Standardisation has shown to have a remarkable influence in reducing the cost and time required for delivering a new school. The long term impact was supported as the most significant measure, however understandably it was suggested that it is a very difficult thing to measure. Many of the schemes that are constructed as a direct result of the James review are yet to reach five years since practical completion and hence considerations such as energy monitoring have not provided substantial data for comparison. This is something that will require patience and repeated monitoring, but will provide more useful benchmarking for future generation of school buildings. Finally the use of standardised school design in addressing the problem of primary school places shortage in UK can offer lessons for other societal problems such as housing. The study however provides the basis for further research to be carried out in different geographical locations and industry context. More importantly is the end-user satisfaction of standardised school buildings delivered so far by the UK government.

\section{References}

Boothman, C, Higham, A and Scott, A (2014) Delivering school buildings using off- site construction: Stakeholders perceptions In: Raiden, A B and Aboagye-Nimo, E (Eds.) Procs 30th Annual ARCOM Conference, 1-3 September 2014, Portsmouth, UK, Association of Researchers in Construction Management, 1017-1026.

BSI (2011), A standard for standards-Principles of standardization' [online] Available at: http://www.iso.org/sites/PEG/docs/PEG\%20Documents/04_bs02011.pdf [Accessed 20 April 2016].

CELE (2011), Standardised design for schools old solution, new context?, International web conference seminar series, Paris: Organisation for Economic Co-operation and Development (OECD) Centre for Effective Learning Environments (CELE).

Coase, R. H. (1937), The nature of the firm, Economical, 4(16), 386-405

Constructing Excellence (CE) (2007), Off-Site production' [Online] Available from: http://www.constructingexcellence.org.uk/pdf/fact_sheet/preassembly.pdf [Accessed on 20 April 2016]. 
Covell, A. (2012), Standardisation-A way forward for school buildings?' [Online] Available at: https://www.fgould.com/uk-europe/articles/standardisation-way-forward-school-buildings, [Accessed April 2016].

Craig, A, Laing, R and Edge, M (2000), The Social Acceptability of Prefabrication and Standardisation in Relation to New Housing. In: 16th IAPS Conference "2 $1^{\text {st }}$ century: Cities, social life and sustainable development", 4 -7 Jul 2000, Paris

Creswell, J. W. (2009), 'Research design: qualitative, quantitative, and mixed methods approaches', (3rd ed.), London: Sage Publications

Department for Education and Skills (DfES) (2005), Departmental Investment Strategy 200508, [online] Available from: http://dera.ioe.ac.uk/6526/1/DIS_20051.pdf [Accessed 10 April 2016].

Department for Education, Education Funding Agency and Laws, D. (2014), Education spending' [online] Available at: https://www.gov.uk/government/speeches/educationspending [Accessed: 10 March 2016].

Edum-Fotwe, F.T., Gibb, A.G. F. and Benford-Miller, M. (2004), Reconciling construction innovation and standardisation on major projects', Engineering, Construction and Architectural Management, 11(5), 366-372.

Education Funding Agency (EFA) and Department for Education (DfE) (2016) 'School capacity: Academic year 2014 to 2015' [online] Available at:

https://www.gov.uk/government/publications /school-capacity-academic-year-2014-to-2015 [Accessed: 1 April 2016].

Fagent, M. (2016), 'Making extra school places add up' [online] Available at: http://0www.building.co.uk.lispac.lsbu.ac.uk/communities/construction/education-andhealthcare/making-extra-school-places-add-up/5073223.article [Accessed: 11 April 2016].

Fox, S. and Cockerham, G. (2000), Matching design and production, The Architects' Journal, 9 March, 50-1

Gardiner, J. (2012), 'Has the Construction Strategy been a success?' [Online] Available at: http://0-www.building.co.uk.lispac.lsbu.ac.uk/has-the-construction-strategy-been-asuccess?/5038630.article [Accessed: 11 April 2016].

Geldard, A. and Griffiths, S. (2011), 'Should standardisation be the future of school design?' [Online] Available at: http://www.bdonline.co.uk/should-standardisation-be-the-future-ofschool-design?/5012830.article [Accessed: 11 April 2016].

Gibb, A. G. F. (2001), Standardization and pre-assembly- distinguishing myth from reality using case study research, Construction Management and Economics, 19(3), 307-315.

Gibb, A. G. F. and Isack, F. (2001), Client drivers for construction projects: Implications for standardization, Engineering, Construction and Architectural Management, 8(1), 46-58. 
Gledson, B. J. (2016), Hybrid project delivery processes observed in constructor BIM innovation adoption, Construction Innovation, Vol. 16 Issue: 2, pp.229-246

Higham, R. (2014), Free schools in the Big Society: the motivations, aims and demography of free school proposers, Journal of Education Policy, 29:1, 122-139

HM Government (2011), 'Government construction strategy' [online] Available at: https://www.gov.uk/government/uploads/system/uploads/attachment_data/file/61152/Govern ment-Construction-Strategy_0.pdf [Accessed: 11 April 2016].

Hoxley, M. (2016), A questionnaire survey of building surveying education', in: V. Ahmed, A. Opoku, and Z. Aziz, (Eds.), Research Methodology in the Built Environment: A Selection of Case Studies, (London, Routledge), pp. 53-64.

James, S. and Brown, E. (2013), 'Review of Education Capital: Progress Update' London, UK: Department for Education.

James, S., (2011), 'Review of Education Capital' [online] Available from: https://www.education.gov.uk/consultations/downloadableDocs/James\%20Reviewpdf.pdf [Accessed 9 November 2015]

Jeffreys, B. (2015), The anxious scramble to get a school place, [online] BBC News, Available at: http://www.bbc.co.uk/news/education-32333911, [Accessed April 2015].

Knight, A. and Ruddock, L. (eds.) (2008), 'Advanced research methods in the built environment', London, Wiley-Blackwell

Linner, T. and Bock, T. (2012), Evolution of large-scale industrialisation and service innovation in Japanese prefabrication industry, Construction Innovation, Vol. 12 Issue: 2, pp.156-178

Livesey, P. (2012), Priority School Building Programme, London: Department for Education (DfE)

McMeeken, R. (2016), ‘School’s Out...of Space’, RICS Modus (April), pp. 34-35.

Omigie, J. (2014), 'The department for education budget after 2015' [online] Available at: https://www.aoc.co.uk/sites/default/files/The\%20Department\%20for\%20Education\%20budg et\%20after\%202015.pdf [Accessed: 15 April 2016].

ONS (2015), 'Construction statistics annual tables' [online] Available at: https://www.ons.gov .uk/businessindustryandtrade/constructionindustry/datasets/constructionstatisticsannualtables [Accessed: 08 April 2016].

Opoku, A., Ahmed, V. and Akotia, J. (2016) Choosing appropriate Research Methodology and Methods, in: V. Ahmed, A. Opoku, and Z. Aziz, (Eds.), Research Methodology in the Built Environment: A Selection of Case Studies, (London, Routledge), pp. 32-49 
Pasquire, C. L. and Gibb, A. G. F (2002), Considerations for assessing the benefits of standardisation and pre-assembly in construction, Journal of Financial Management of Property and Construction, 7(3), 151-161.

Polesie, P., Frödell, M., and Josephson, P. (2009), Implementing standardisation in medium sized construction firms: Facilitating site managers' feeling of freedom through a bottom up approach, Proceedings for the 17th Annual Conference of the International Group for Lean Construction, International Group for Lean Construction, 317-326.

Richardson, S. (2016), 'Cost of meeting school places crisis could hit £18bn' [online] Available at: www.building.co.uk/news/cost-of-meeting-school-places-crisis-could-hit18bn/5073200.article [Accessed: 17 April 2016].

Robson, C. (2011), 'Real world research: A resource for users of social research methods in applied settings', (3rd edn.), United Kingdom: John Wiley \& Sons.

Robinson, A. Gibb A. and Austin, S. (2012), Standardisation of specification driven buildings with serial and repeat order designs In: Smith, S.D (Ed) Procs 28th Annual ARCOM Conference 3-5 September 2012, Edinburgh, UK, Association of researchers in Construction Management, 57-66

Russell, A. L., (2005), Standardization in history: a review essay with an eye to the future', The standards edge: Future generations, pp.247-260.

Salama, M, Al-Sharif, F, Kaka, A P, and Leishman, C. (2006), Cost modelling for standardised design projects. In: Boyd, D (Ed) Procs 22nd Annual ARCOM Conference, 4-6 September 2006, Birmingham, UK, Association of Researchers in Construction Management, 621-631

Saunders, M., Lewis, P. and Thornhill, A. (2000), 'Research Methods for Business Students', 2nd Ed Financial Times/Prentice Hall, Harlow

Scape, (2016) 'Scape - public sector built environment specialist', [online] Available at: http://www.scapegroup.co.uk/ [Accessed: 4 May 2016].

Southern construction framework (SCF), (2016), Southern construction framework (SCF), [online] Available at: http://www.southernconstructionframework.org.uk/pages/homescf.html, (Southern Construction Framework (SCF), [Accessed: 4 May 2016].

Smith, A. (1977), An inquiry into the Nature and Causes of the Wealth of Nations, Chicago, IL: University of Chicago Press.

Sundbo, J. (2002), 'The Service Economy: Standardisation or Customisation?', The Service Industries Journal, 22:4, 93-116

Talbot, D. and Francis, S. (2012), 'Cost Model: Standardised School Solutions' [online], Available at: http://www.aecom.com/deployedfiles/Internet/Capabilities/Program,\%20Cost,\% 20Consultancy/Cost/Schools_CM_17Feb12.pdf [Accessed 12 April 2016] 
Tse, H.M., Learoyd-Smith, S., Stables, A. and Daniels, H. (2015), Continuity and conflict in school design: a case study from Building Schools for the Future, Intelligent Buildings International, 7(2-3), 64-82.

Williamson, O. E. (1975), Markets and hierarchies: Analysis and Antitrust implications, pp. 26-30, New York: The Free Pres.

Williamson, O. E. (1989), Transaction cost economics, Handbook of industrial organization, 1, pp.135-182. 